\title{
A indústria Farmacêutica no Brasil e o uso da TI como instrumento de decisões
}

Vitor Hugo Strozzi

\begin{abstract}
Mestrando do Programa de Administração do Centro Universitário Positivo
Resumo. O trabalho busca analisar o uso da tecnologia da informação como elemento de decisões estratégicas e táticas pela indústria farmacêutica. Para encontrar estas respostas, definiu-se como principal objetivo estudar a questão da rastreabilidade e seu uso como elemento gerador de informações úteis para decisões gerenciais. Observa-se o fluxo do produto pela supply chain e pesquisa-se nos agentes os formatos e procedimentos utilizados para que a informação seja gerada e os clusters montados e analisados.

O trabalho apresenta dois levantamentos: o teórico, com base na bibliografia existente sobre o assunto, e o prático, que se baseia em dados levantados em pesquisa exploratória. Ambos são confrontados na conclusão, permitindo a identificação da forma como o setor utiliza a informação da cadeia de suprimentos para aperfeiçoar o seu negócio.
\end{abstract}

\section{INTRODUÇÃO}

Este trabalho objetiva analisar a rastreabilidade dos medicamentos durante o processo de transferência até o consumidor final, bem como, estudar o modelo de gestão de dados com uso da tecnologia da informação pela indústria farmacêutica.

Busca-se comprovar que foram criados mecanismos adequados para rastrear os produtos comercializados, identificando-se o labirinto logístico percorrido até a entrega para o consumidor final.

Cumprida esta etapa procura-se verificar se a indústria tem áreas de inteligência de mercado que analisam estes dados e orientam os executivos para suas tomadas de decisões. As informações vêm de fora para dentro e pretende-se focalizar a natureza do processo e o grau de aproveitamento dado a estes números para tomar decisões estratégicas, táticas ou ambas.

A indústria farmacêutica é parte do cotidiano das pessoas e, como tal, objeto de muita informação e propaganda, justificando, portanto, do ponto de vista prático, a realização de estudos para verificar a importância da informação em seu processo de tomada de decisões.

Este artigo apresenta sucinta revisão bibliográfica sobre tecnologia da informação e rastreabilidade, depois propõe uma pesquisa e demonstra a metodologia utilizada, analisa os dados coletados e os compara com a revisão bibliográfica e, na conclusão, identifica se as hipóteses propostas foram confirmadas. 


\section{SISTEMAS DE INFORMAÇÃO}

De acordo com Epstein (1960), “informação é conceito que adquire significado apenas em um dado contexto.” Na definição de Rezende e Abreu (2001), tecnologia da informação pode ser conceituada como "recursos tecnológicos e computacionais para geração e uso da informação” (p. 76).

O mundo atual é o mundo do tempo real, "que se caracteriza pela imensa proximidade entre a idéia e a ação, entre iniciar uma tarefa e concluí-la” (McKENNA. 1998, p. 26) e dispõe de arsenal tecnológico que propicia a geração contínua de dados. O grande volume de dados gerados em qualquer operação, contudo, dificulta a sua conversão em informações. No novo ambiente, é mais difícil escolher entre as informações disponíveis do que obtê-las. Para Graeml (2000, p. 19), "até a década de 70, as grandes mudanças eram indicadas por sinais fortes. A partir de então, elas começaram a ser anunciadas por um número muito maior de sinais cada vez mais fracos, perdidos no meio de tanta informação disponível".

O ambiente de negócios passou a contar, desde a década de 1950, com o apoio de sistemas ordenados de informação (management information systems), determinando uma certa estrutura aos dados (Kotler, 2000). Na década de 1970, surgiram os chamados sistemas de suporte à decisão (decision support systems), de acordo com Alter (1983). Depois vieram, na década de 1980, os sistemas especialistas (expert systems), conforme salienta Ignizio (1991) e, a partir do final dos anos 1980 e do inicio da década de 1990, apareceram os sistemas de informação estratégica (strategic information systems), defendidos, entre outros, por Porter (1987) e Mintzberg (1996).

A implantação destes sistemas sustenta-se, sempre, em pelo menos dois elementos críticos: redução constante do custo da tecnologia e melhoria contínua das linguagens de interação entre os equipamentos e os usuários. As empresas compuseram, neste período, desde sistemas orientados para controles, nos primeiros tempos, até os atuais sistemas de gerenciamento estratégico.

Diferentemente do que se vê nos países mais desenvolvidos, uma pesquisa desenvolvida por Leite (2004) demonstra que o nível de prioridade do uso de TI por executivos de empresas brasileiras ainda está longe do campo estratégico. Para esse autor, "a preferência dos executivos estava fortemente concentrada nos projetos que geram economia. Ao mesmo tempo, havia forte propensão a rejeitar projetos ligados ao processo decisório e ao uso estratégico de TI” (p. 84).

Leite (2004) afirma, ainda, que o cenário tem dois componentes: um quantitativo, que corresponde à categoria "save cost”, usado para análise da capacidade operacional, e o outro corresponde a melhorias no processo decisório e uso estratégico, quando "qualquer critério quantitativo tende a ser inerentemente subjetivo o que faz com que os números gerados sejam frágeis por definição, ampliando as chances de rejeição do projeto.” (p. 85).

Segundo Falk (2006), "para aumentar o lucro, as empresas farmacêuticas costumam utilizar três estratégias: aumento de preço, maior volume de vendas e menor custo. A primeira opção, contudo, está sendo regulada com bastante rigor pelo governo 
(brasileiro). O que resta, portanto, são estratégias para aumentar o volume de prescrições e/ou programas de controle de custos e eliminação de ineficiências operacionais.” (p. 130).

Esse mesmo autor afirma que "pode-se confirmar que o simples uso de computadores não significa mais uma vantagem competitiva.” De maneira clara, conclui-se com ele que "é muito difícil encontrar no setor farmacêutico, especialmente no Brasil, uma empresa totalmente integrada, tanto interna, quanto externamente.” (p. 130).

A indústria farmacêutica está ligada à tecnologia. Rezende e Abreu (2001) afirmam que políticas associadas ao conhecimento situam-se no campo das "políticas estratégicas emanadas da alta administração da empresa...” em contraposição “às políticas operacionais que orientam as atividades quotidianas e os procedimentos básicos. Em decorrência das políticas estratégicas também são geradas as políticas de informação que influenciam e contemplam os sistemas de informação” (p. 168).

O governo impôs à indústria farmacêutica a obrigatoriedade do acompanhamento permanente de produtos durante todo o "shelf-life". A este procedimento dá-se o nome de rastreabilidade, que, de acordo com a definição publicada no site da EAN BRASIL (2006) é:

...mais do que um instrumento para facilitar as transações comerciais $e$ administração de negócios, tem sido uma condição essencial nos mercados interno e externo, na medida em que coloca em xeque todas as fases da cadeia produtiva.

Na área da saúde, particularmente, essa tecnologia tem sido a forma de gerar no setor a transparência que sempre se desejou...

A rastreabilidade é um imperativo de segurança para os pacientes e para toda a cadeia de medicamentos em qualquer lugar do mundo. Como conseqüência da rastreabilidade, a indústria farmacêutica passou a dispor de dados sobre mais de 1,5 bilhão de unidades de medicamentos, enquanto estes se encontram em trânsito.

Em análise desfavorável ao setor farmacêutico no Brasil, Falk (2005) afirma que "poucas experiências com Web Services estão atualmente em andamento, especialmente no que se refere às atividades ligadas com o negócio central da empresa.” (p. 117). Falk afirma, ainda, que as alternativas disponíveis de TI nesta indústria estão focadas na redução de custos, sem foco na especialização.

\section{METODOLOGIA}

Este trabalho baseia-se em dois tipos fontes:

1. Fonte bibliográfica, com base em livros, sites e artigos que fornecem a sustentação teórica e o levantamento das oportunidades de validação das informações coletadas;

2. Pesquisa qualitativa exploratória, não aleatória, com executivos de empresas de prestadoras de serviço de informação, executivos de associações representativas de segmentos da indústria de farmacêuticos e executivos responsáveis pelo setor de inteligência de mercado em indústrias farmacêuticas. 
Para participar da pesquisa qualitativa foram escolhidos dois executivos que presidem associações de classe que representam um rol de indústrias e o atacado farmacêutico, totalizando mais de $90 \%$ do mercado de produtos de prescrição (entrevistados 1 e 2). Embora o número de entrevistados seja pequeno, seu lugar no topo das duas pirâmides empresariais valida o conjunto de informações que são apresentadas e, mais do que isto, estimula a se fazer estudos mais amplos, complementares aos realizados para este artigo.

Além dos executivos das associações de classe, foram entrevistados também seis executivos (entrevistados 3, 4, 5, 6, 7 e 8), que se dispuseram a responder dentre os integrantes das quatro VANs (value add networks) - TIVIT, IMS, GENEXIS e,estudando a entrada no mercado, o IBOPE, empresas que usam tecnologia como meio de transporte de dados e documentos.

\section{ANÁLISE DA INDÚSTRIA FARMACÊUTICA NO BRASIL COM BASE EM DADOS EXTRAÍDOS DA PESQUISA QUALITATIVA}

A indústria farmacêutica é uma das mais sensíveis às pressões da sociedade. Sua evolução de indústria quase artesanal, dominada por chás e poções mágicas até os finais do século XIX, em pouco mais de cem anos, transformou-a em um dos mais sofisticados, senão o mais sofisticado ramo do complexo químico.

Sua dedicação à pesquisa tem acompanhado o surgimento de novos ferramentais para o processo de desenvolvimento de fármacos. Os estudos sobre o genoma humano, por exemplo, são utilizados desde seu inicio para a identificação da origem de distúrbios derivados dos desarranjos genéticos. (LEVY, 2002, p. 3)

Esta indústria, devido à sua relevância e às necessidades de segurança sanitária da população, é controlada pelo governos e pelos chamados órgãos regulatórios. A Agência Nacional de Vigilância Sanitária (ANVISA), no Brasil, é a agência governamental, conforme definição encontrada em seu site na Internet, que tem por missão "proteger e promover a saúde da população, garantindo à segurança sanitária de produtos e serviços e participando da construção de seu acesso.”

A indústria farmacêutica é responsável pela qualidade do produto até o cliente final que compra o produto na farmácia.

Esta responsabilidade implica que a indústria saiba para quem é vendida e onde permanece cada unidade de produto durante todo o "shelf life". Mas ela também permite que a indústria possa se defender, identificando atravessadores e/ou receptadores que estejam colocando produtos falsos, danificados ou roubados no mercado. A figura 2 é um espelho da cadeia farmacêutica e demonstra que 1,5 bilhões de unidades transitam por mais de 110.000 pontos de vendas no país, desde farmácias até, em alguns casos, armazéns.

Conforme o exposto na figura 2, na fase inicial da comercialização a indústria tem total controle sobre o destino dos produtos. Segundo a ABAFARMA - Associação Brasileira do Atacado Farmacêutico, (entrevistado 1) que têm associados que representam aproximadamente $90 \%$ da distribuição de medicamentos, excetuando-se as redes de farmácias e drogarias, todas as notas fiscais identificam o lote de cada medicamento 
vendido, isto tanto no fluxo da indústria para os atacados e outros agentes, quanto dos atacados para as farmácias.

\section{FIGURA 2 - CADEIA PRODUTIVA DE PRODUTOS FARMACÊUTICOS}

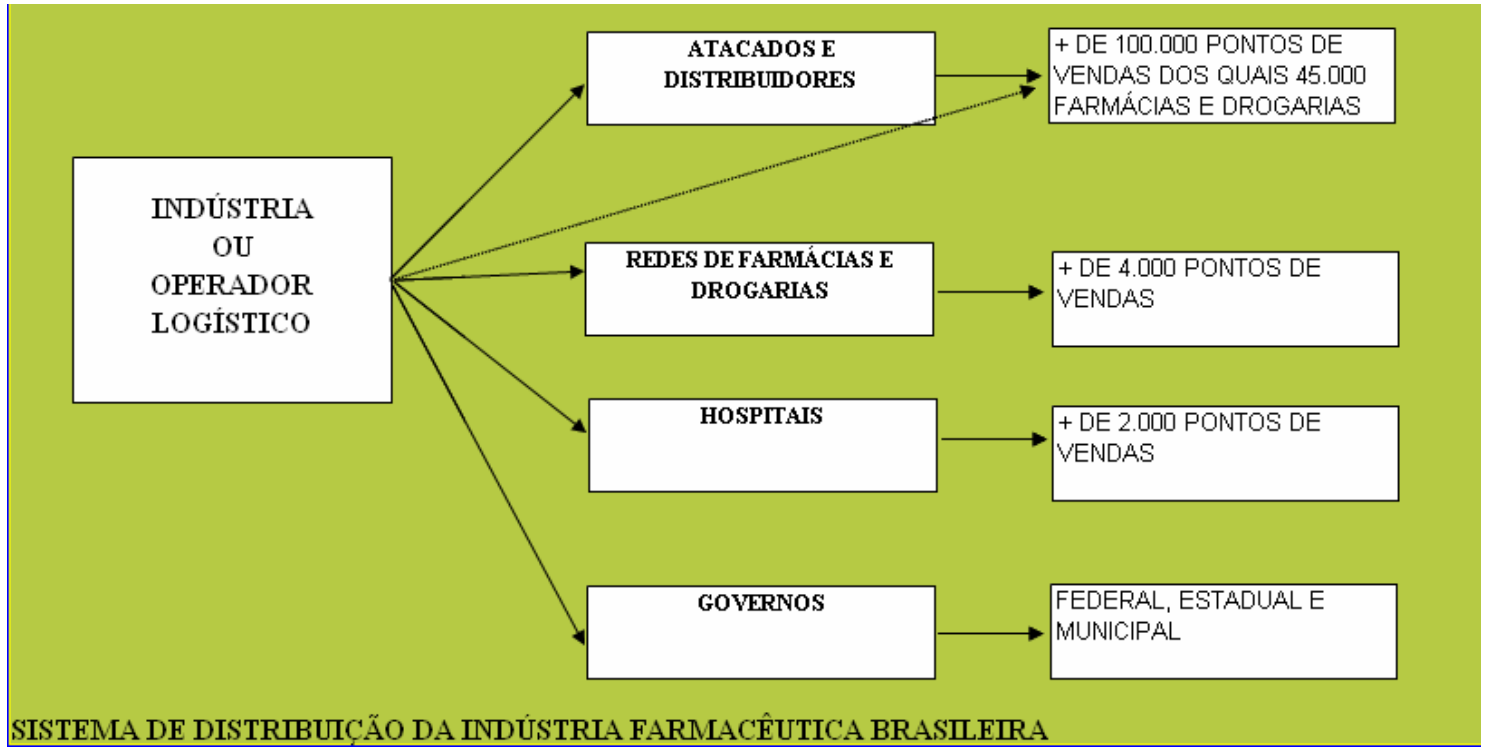

Fonte: figura elaborada pelo autor com base em dados fornecidos pelos pesquisados.

Um executivo de companhia gerenciadora de EDI (electronic data interchange) confirma que a empresa presta serviços para mais de 40 laboratórios que utilizam o sistema para receber seus pedidos (entrevistado 3). Esta forma de conectividade vem sendo utilizada no Brasil desde a década de 90 e, embora criticada pelo engessamento de transferência somente de dados, sem a negociação pedido a pedido, seu uso vem sendo cada vez mais comum e estes laboratórios respondem por uma participação de mercado superior a $70 \%$.

Os pedidos são coletados em caixa postais pelo fabricante que os autoriza e fatura em seus armazéns ou em empresas de logística prestadoras de serviços. Segundo, o executivo 3, a regra é não haver contato com os pedidos e o faturamento, exceto quando há problemas de créditos ou falta de produtos para atender a demanda.

Quando o produto chega aos atacados, distribuidores ou redes atacadistas, muitas vezes são colocadas etiquetas, fato gerado, segundo a Abafarma (entrevistado 1) pelo fato de que as unidades de medicamento não têm identificação do lote em código de barras na própria embalagem do produto, o que obriga os atacados, distribuidores e redes a identificarem cada produto, uma vez que a caixa de embarque que veio fechada da indústria é aberta e o produto é separado por unidades para venda.

Esta fonte (entrevistado 1) estima que, durante o ano de 2007, este sistema será substituído por um sistema mais sofisticado, que identificará cada unidade que sair da indústria com o número do lote.

Quando os atacados ou os depósitos das grandes redes encaminham os produtos para os mais distintos pontos de vendas geram, por obrigação legal, notas fiscais, que contêm verdadeira mina de dados, que podem se converter em informação. Em análise sucinta, 
uma nota fiscal contém a identificação do cliente, seu endereço, seu nome comercial, a quantidade de unidades vendidas, a apresentação dos produtos vendidos e o lote de fabricação, o valor destes produtos e outros dados menos relevantes.

Este conjunto de dados pode se transformar em informações e permitir à indústria formular, implantar e avaliar suas estratégias mercadológicas.

Desde a década de 1970, a indústria farmacêutica tem empresas coletando dados de mercado no Brasil. Segundo o entrevistado 5, a primeira a se instalar em solo brasileiro foi o IMS Health, uma empresa do grupo Dun \& Bradstreet. Na década de 1990 foi fundada a Servix, que mais tarde se transformou na GENEXIS, e, por fim, a PROCEDA criou uma divisão para coletar estes dados, processá-los e ordená-los de forma que se convertessem em informações fáceis de ser analisadas.

A oportunidade que surgiu para as duas últimas empresas, segundo o entrevistado 5, deveu-se ao fato de que, naquela época, a coleta e validação de dados feita pelo IMS tinha um "delay" superior a 90 dias entre a coleta de dados e o recebimento das informações pela indústria. Outro ponto importante era o alto custo dos serviços oferecidos pelo IMS. A SERVIX, hoje GENEXIS, passou a oferecer os mesmos dados dois dias após a coleta e com processamento on-line. Em seguida, a Proceda, hoje TIVIT, que estava interessada no negócio de pedidos eletrônicos, via EDI, entrou no negócio. No mês de agosto de 2006, a GENEXIS foi adquirida pela IMS.

Segundo o entrevistado 6, outro executivo do setor, em agosto de 2006 havia 19 indústrias do segmento que eram clientes da TIVIT e 20 da GENEXIS. Por imposição das casas matrizes, a maior parte dos laboratórios de multinacionais compra os serviços destas e o produto do IMS, porque este é um instituto com atuação e reconhecimento internacional.

Segundo o entrevistado 2, o acompanhamento dos produtos éticos - também chamados de produtos de prescrição - e dos produtos OTC (over the counter) - também chamados de produtos de venda livre - das grandes indústrias é feito em sua totalidade. Por outro lado, o controle sobre genéricos e similares é menor.

Segundo a ABAFARMA (entrevistado 1), as informações são enviadas diariamente pelos atacadistas. As redes repassam as informações diariamente ou semanalmente. Estes dados são processados e disponibilizados no site das VANs.

Feito o processamento, os departamentos de inteligência de mercado e de vendas, segundo o entrevistado 4, passam a minerar os dados e a interpretá-los. Os números passam a adquirir significado, já que se relacionam diretamente a um dado contexto, que está sendo analisado em suas múltiplas bases (tempo, geografia, produto etc.).

A indústria está trabalhando com um delay de apenas um ou dois dias nas informaçõe sdisponíveis, o que lhe permite agir operacionalmente com precisão sobre mercados ou clusters específicos, que não estão respondendo satisfatoriamente às ações de marketing ou aos esforços das equipes de vendas. Qualquer situação mapeada com resultados fora do esperado pode ser analisada, para que se tomem as devidas medidas. Segundo vários dos executivos pesquisados (entrevistados 1, 3, 6, 7 e 8), os gerentes regionais e distritais são capazes de verificar, com suas senhas e notebooks, como seus territórios e clientes operam e podem agir taticamente, porque estão no campo. Tomar medidas e ações de incremento de vendas é uma conseqüência esperada da capacidade de 
compreender os dados disponibilizados. No entanto, segundo o executivo 4, a indústria é carente de profissionais capazes de tratar adequadamente os dados significativos e tomar as providências necessárias em tempo real.

Para todos os entrevistados, a grande indústria farmacêutica no país formula suas estratégias com base nos dados coletados e nas conclusões dos analistas, enfatizando que, em períodos de planejamento estratégico e de formulação dos orçamentos, distintas áreas os estudam e analisam, tomando decisões a partir deles.

Um dos executivos pesquisados (entrevistado 2) enfatizou que os principais usuários dos dados disponibilizados, ao longo do ano, são os gerentes e diretores de marketing e, em algumas empresas, os chamados gerentes de produtos. Estes executivos são os principais formuladores das estratégias de produtos nestas empresas.

O modelo merece críticas, feitas pelos entrevistados 2 e 5 :

1. Os dados sobre vendas chegam até o intermediário, isto é, até o varejista, de qualquer porte, e aos hospitais. No entanto, idealmente, seria melhor se a informação identificasse o paciente usuário do produto, possibilitando o monitoramento de todas as vendas feitas a clientes que aceitassem ser identificados;

2. Os analistas que geram a informação a partir dos dados brutos são um conjunto pequeno de profissionais, ainda em desenvolvimento. Além disto, há um alto nível de turn-over, já que o número de indústrias que se utilizam-se das ferramentas de mercado é cada vez maior, o que aumenta a necessidade de analistas com sensibilidade aos problemas de campo, algo que só se adquire com o tempo;

3. O grau de concorrência entre os atacadistas é tão acirrado que impede a formação de empresas orquestradoras, como as preconizadas por Falk (2006).

A crítica manifestada no item 1 é procedente. O conjunto de informações que os atacadistas fornecem identifica apenas o intermediário, quer seja uma farmácia, uma drogaria ou um hospital. Existem, nos Estados Unidos, empresas chamadas pharmacy benefit management (PBM) que gerenciam as informações sobre os pacientes. Estas empresas prestam serviços a seguradoras, clinicas e laboratórios farmacêuticos, principalmente porque são elas que organizam o reembolso, dispondo de dados sobre o paciente e sua relação com a companhia seguradora.

Este modelo, segundo um dos pesquisados (entrevistado 5) será implantado no Brasil em algum momento futuro, mas é difícil precisar quando, porque o setor de seguros ainda está em expansão e, portanto, tem outras preocupações mais prementes. E, no que interessa à indústria farmacêutica, que é encontrar mecanismos de aprisionamento do cliente a determinados tratamentos, já existem prestadoras de serviços, que prestam vários destes serviços, tendo sido citadas a E-PHARMA e a PREV-SAUDE, que usam tecnologias de CRM (Customer Relationship Management). ${ }^{1}$

A segunda crítica, segundo todos os pesquisados, é difícil de resolver, porque o analista de inteligência do mercado é um profissional muito completo, a quem não basta

\footnotetext{
${ }^{1}$ Para maior conhecimento verificar os sites www.epharma.com.br e www.prevsaude.com.br .
} 
compreender o dado isoladamente, mas dentro do contexto em que ele aparece, o que o torna escasso no mercado profissional.

A terceira crítica é a mais complexa de todas. Falk (2005) sugere um modelo semelhante ao de outros países, esquecendo de dados importantes sobre o mercado distribuidor brasileiro. Segundo o executivo da ABAFARMA (entrevistado 1) existem mais de 300 distribuidores e atacadistas no Brasil, mas apenas 20, somados a 25 redes, respondem por $90 \%$ do mercado de medicamentos de prescrição no Brasil. O modelo americano de distribuição aprisiona as farmácias e hospitais mediante contratos e parcerias consistentes, segundo o entrevistado 7, diferentemente do modelo praticado no Brasil, cuja concorrência é maior, tornando desinteressante para os compradores os contratos de qualquer natureza que impliquem em exclusividade de compra. Nem a indústria dá exclusividade ao atacadista, analisando-se a cadeia de valor à montante, nem as farmácias lhe são exclusivas, à jusante. Imprensado pelos dois lados, torna-se impossível para o atacadista atuar como "orquestrador" da cadeia, como sugerido por Falk (2005). Portanto, o domínio continua do lado do fabricante.

\section{CONCLUSÃO}

A análise das informações repassadas pelos entrevistados demonstra que certos conceitos são, na verdade, preconceitos e podem induzir a análises errôneas sobre o setor farmacêutico e sobre a forma como ele se utiliza de uma rede de informações sofisticada, como em poucos setores no Brasil.

A rastreabilidade, por exemplo, poderia transformar-se em ônus para a indústria farmacêutica, mas embora a ANVISA a julgasse inexistente, a mesma já era prática corrente das grandes indústrias. Se a legislação e os regulamentos a este respeito advém do início deste século, com a criação da ANVISA, e se a indústria já dominava dados desde a década de 1990 do século XX, conforme evidenciado, pode-se concluir que sua regulamentação, tão somente, institucionalizou prática corrente no mercado.

Deduz-se da afirmação de um dos pesquisados (entrevistado 2) que a imposição legal tinha objetivo de universalizar o uso da prática por todos os laboratórios, uma vez que, com a obrigatoriedade da rastreaabilidade, o governo estaria mais seguro em casos de recall ou de fraudes. Em qualquer dessas situações, identifica-se facilmente o local onde estão os produtos objeto de retirada, e, em caso de infração, pode-se identificar o falsificador e os varejistas que colocam o produto falsificado no mercado.

A conversão de dados em informações, isto é, em ordenamento adequado para a tomada de decisões, gerou duas opiniões distintas entre os entrevistados, de um lado, a maioria assegura que é feito uso estratégico e tático das informações e, de outro lado, um dos informantes (entrevistado 5) afirma que há carência de analistas para comporem estas análises de forma satisfatória, embora elas tenham cunho nitidamente estratégico.

Como são dois conceitos distintos, pode-se concluir que a indústria, por conseqüência da necessidade de rastrear os produtos, entendeu que aquele amontoado de dados deveria ser usado para a tomada de decisão e, a partir do uso das próprias VANs como data warehouses, analisa os dados e utiliza as tecnologias que estão ao seu dispor para entender o mercado e fixar suas estratégias. Esta é outra conclusão crucial. De um lado, o pessoal de marketing utiliza as informações como instrumentos de planejamento e 
ação estratégica mercadológica, de outro, o pessoal de campo as usa como instrumento de ações táticas de vendas e de ganhos pontuais de mercado.

Discorda-se, por isto mesmo, de duas afirmações de Falk (2005). Na primeira, aquele pesquisador induz o leitor a entender que a supply-chain da indústria farmacêutica é desestruturada e pouco intensiva no uso de tecnologias da informação, considerando que há pouco uso da informação como elemento de decisão estratégica. Como se pôde perceber, ocorre exatamente o oposto.

A indústria farmacêutica atou o mercado a formatos que entende necessários para suas decisões estratégicas e táticas. Com a concessão de dados a partir da nota fiscal do atacadista e da nota de transferência das redes, é possível a geração intensiva de informações, bastando para isto que haja esforço analítico de parte das equipes de gestão estratégica e tática dos interessados.

Na segunda afirmação, Falk (2005) conclui que a informatização da indústria se concentra em questões periféricas e relacionadas à redução de custos, estando no que ele chama de primeiro estágio de conectividade de Hage. Não é isto que a pesquisa demonstra. Os entrevistados são unânimes quando afirmam que a indústria está usando a informação para a tomada de decisões estratégicas. Ora, esta visão é a proposta no terceiro estágio de Hage, quando o importante é o foco na alavancagem dos negócios.

Como McKenna (1998) imaginava, as empresas, quase sem perceber, estão se transformando em empreendimentos em tempo real. O conjunto de informações obtido, diferentemente do que identificou Leite (2004) em sua pesquisa, que tinha um caráter mais geral, não se detendo especificamente sobre a indústria farmacêutica, é usado nesta indústria com clara finalidade estratégica. A excelência e domínio têm sido conquistados por empresas que conseguem utilizar a informação disponível a cada instante para ocupar e re-ocupar, permanentemente, sua posição em um mercado altamente competitivo.

\section{REFERÊNCIAS BIBLIOGRÁFICAS}

EPSTEIN, I. Cibernética e Comunicação, São Paulo: Cultrix, 1960.

FALK, James A. Caminho livre para crescer. In: Lucratividade pela Inovação : como eliminar ineficiências nos seus negócios e na cadeia de valor / Microsoft - Rio de Janeiro : Elsevier. São Paulo: Microsoft Brasil, 2005.

GRAEML, Alexandre R. Sistemas de informação: o alinhamento da estratégia de TI com a estratégia corporativa. São Paulo: Atlas, 2000.

KOTLER, Philip. Administração de marketing: a edição do novo milênio / trad. Bazan Tecnologia e Lingüística. São Paulo: Prentice Hall, 2000.

LEITE, Jacy Corrêa. Decisões de investimentos em tecnologia da informação. In: Tecnologia da informação / Alberto Luiz Albertin, Rosa Maria de Moura (orgs.). São Paulo: Atlas, 2004.

McKENNA, Regis, Tiempo Real, Cómo prepararse para la era del cliente nunca satisfecho / trad. Emilia Ghelfi. Buenos Aires: Temas Grupo Editorial, 1998. 
MINTZBERG, Henry e QUINN, James Bryan. The strategic process - concepts, contexts, cases. Upper Saddle River: Prentice Hall Inc. 1996.

PORTER, Michael E. From competitive advantage to corporate strategy. Harvard Business Review, May-June 1987.

IGNIZIO, James. Introduction to expert systems: The development and implementation of rule-based expert systems. Burr Ridge: MacGraw Hill Higher Education, 1991.

LEVY, Clayton. Inovação gerada no campus. Jornal da Unicamp - número 193, Universidade Estadual de Campinas. 2002.

REZENDE, Denis Alcides, ABREU, Aline França de. Tecnologia da Informação aplicada a sistemas de informação empresariais : o papel estratégico da informação e dos sistemas de informação nas empresas. 2.ed. São Paulo: Atlas, 2001. 